\title{
A prospective study of the association between drainage volume within 24 hours after thoracoscopic lobectomy and postoperative morbidity
}

\author{
Ryoichi Nakanishi, MD, PhD, ${ }^{a}$ Yoshihisa Fujino, MD, MPH, PhD, ${ }^{\mathrm{b}}$ Toshihiro Yamashita, MD, ${ }^{a}$ and Soichi Oka, MD
}

Objectives: We prospectively analyzed the association between drainage volume and development of complica-
tions to clarify the safety of early removal of chest tube after thoracoscopic lobectomy.

\begin{abstract}
Methods: Between November 2001 and October 2007, 136 patients with suspected or histologically documented lung cancer were enrolled. Patients with no air leak and increased drainage underwent removal of the chest tube on the day after thoracoscopic lobectomy independent of the drainage volume. Patients were classified into three groups as tertiles according to the drainage volume. Demographic and perioperative variables were compared among the three groups. Age-sex adjusted odds ratios of the clinical variables associated with development of complications were estimated. In addition, the odds ratios of the drainage volume for development of complications were estimated after adjusting for potentially important factors.
\end{abstract}

Results: One hundred patients underwent early removal of the chest tube. Almost all demographic and perioperative variables showed no differences among the three groups $(0-289 \mathrm{~mL}, \mathrm{n}=33 ; 290-399 \mathrm{~mL}, \mathrm{n}=33$; and $\geq 400 \mathrm{~mL}, \mathrm{n}=34$ ). Tumors in a lower lobe, preoperative stage II or higher, 5 or more anatomic segments resected, and advanced disease were all factors that were associated with higher odds ratios for complications. The drainage volume was not associated with an increased morbidity, even after adjusting for these factors.

Conclusions: Early removal of chest tube on the day after thoracoscopic lobectomy, independently of the drainage volume, appears to be safe in well-selected patients.

The pleural space is routinely drained after a pulmonary lobectomy because re-expansion of the remaining lung tissue, with the natural obliteration of the pleural space and without any major fluid collection, is the desired clinical goal. Conventionally, the chest tubes are kept in the pleural space until air leakage has ceased and drainage is less than $150 \mathrm{~mL}$ for the prior 24 hours. ${ }^{1}$ To date, to our knowledge, no clear evidence concerning the proper drainage volume in regard to the optimal timing of chest tube removal has been reported in the literature.

Some investigators have reported a streamlining of the normal health care protocol to be potentially feasible after a pulmonary resection through a muscle-sparing thoracotomy. Cerfolio and associates ${ }^{2,3}$ demonstrated that chest tube removal on postoperative days 2 to 3 was not associated with any significant morbidity even in patients who underwent major pulmonary resections. Nomori and colleagues ${ }^{4}$ reported that the early removal of chest tubes on postoperative

\footnotetext{
From the Department of Thoracic Surgery, Shin-Kokura Hospital, Federation of National Public Service Personnel Mutual Aid Associations, ${ }^{\mathrm{a}}$ and the Department of Preventive Medicine and Community Health, University of Occupational and Environmental Health, ${ }^{\text {b }}$ Kitakyusyu, Japan.

Received for publication Aug 1, 2008; revisions received Sept 17, 2008; accepted for publication Oct 26, 2008

Address for reprints: Ryoichi Nakanishi, MD, PhD, Chief, Department of Thoracic Surgery, Shin-Kokura Hospital, Federation of National Public Service Personnel Mutual Aid Associations, 1-3-1 Kanada, Kokurakita-ku, Kitakyusyu 803-8505, Japan (E-mail: ryoichi@med.uoeh-u.ac.jp).

J Thorac Cardiovasc Surg 2009; 137:1394-9

$0022-5223 / \$ 36.00$

Copyright (c) 2009 by The American Association for Thoracic Surgery doi:10.1016/j.jtcvs.2008.10.035
}

days 1 to 3 could accelerate the recovery of the "6-minute walking distance" while resulting in minimal complications in patients with lung cancer who underwent a lobectomy. In all three studies, a drainage volume of less than approximately $400 \mathrm{~mL}$ for the previous 24 hours, as well as the absence of air leakage, were the necessary requirements for chest tube removal. However, the reasons for such a protocol concerning the drainage volume for the timing of chest tube removal were unclear.

With this background, we designed this prospective cohort study to elucidate the association between the drainage volume and postoperative morbidity to clarify the safety of early removal of chest tubes after lobectomy done by video-assisted thoracic surgery (VATS).

\section{PATIENTS AND METHODS \\ Patient Selection}

Between November 2001 and October 2007, 136 patients with suspected or histologically documented lung cancer were enrolled in this prospective study. This series includes consecutive patients for whom the preoperative intention was to perform a VATS major pulmonary resection, including a lobectomy or bilobectomy, and to perform a mediastinal lymph node dissection. The indications for a VATS lobectomy were based on the standard criteria for an open thoracotomy, including tumors up to $6 \mathrm{~cm}$ in diameter. This study excluded any patients who underwent a pneumonectomy. The patients who were included had an Eastern Cooperative Oncology Group performance status of 0 to 2 . All patients with radiologically suggestive limited single-station N2 disease were eligible for this study. This series included 1 patient who underwent induction chemotherapy. In patients with preoperative stage IV, only treatable brain metastasis was included. The Institutional Review Board of Clinical Research of our hospital ethically 


\section{Abbreviation and Acronym \\ VATS $=$ video-assisted thoracic surgery}

approved this study, and informed consent for this study was obtained from all patients.

\section{Surgical Technique}

Under single-lung anesthesia, 4 incisions were used in the majority of the patients in this series. A utility thoracotomy was placed in the third or fourth intercostal space and consisted of a 5- to 7-cm incision. The remaining 3 incisions for the $12-\mathrm{mm}$ trocars were made. The pulmonary vessels and bronchi were then individually divided and an extensive dissection of the mediastinal lymph nodes was thoracoscopically performed, as previously reported. ${ }^{5-7}$ After pneumostasis and hemostasis were confirmed, a $28 \mathrm{~F}$ chest tube was placed in the apical and posterior pleural space through the trocar wound on the anterior axillary line. Moreover, a small 7F backup tube was placed within the dead space by thoracoscopic guidance for all patients to prevent excessive fluid accumulation, potentially caused by the early removal of the $28 \mathrm{~F}$ tube. The wounds were then closed. Only a $28 \mathrm{~F}$ tube was kept on suction with a negative pressure of $10 \mathrm{~cm} \mathrm{H}_{2} \mathrm{O}$ until removal in all patients to decrease the size of the dead space.

\section{Study Design and Data Acquisition}

We established the clinical criteria for this early removal strategy of the chest tube as follows, with reference to a previous work by Russo and coworkers. $^{8}$

1. Absence of air leakage

2. Absence of an increased drainage volume every 6 hours after surgery

3. Absence of a densely bloody, purulent, or cloudy pleural effusion

4. Absence of atelectasis on postoperative chest radiograph

5. Orotracheal tube removal after recovery from anesthesia

The patients who met these criteria underwent early removal of the $28 \mathrm{~F}$ chest tube on the day after VATS lobectomy, independent of the drainage volume. The 7F backup tube was removed on the fourth postoperative day when all went smoothly. The patient underwent rescue drainage through the $7 \mathrm{~F}$ tube when he or she had subjective symptoms (eg, cough, dyspnea on exertion, or chest discomfort) or compression atelectasis on chest $\mathrm{x}$-ray films.

The operative mortality included all patients who died within the first 30 days after surgery or during the hospitalization. The postoperative morbidity included all patients who had complications during the hospitalization and after discharge from the hospital. The complete follow-up data were obtained from the records of the postdischarge visits and from the regular radiographic follow-up.

\section{Statistical Analysis}

The subjects were classified into three groups as tertiles according to the drainage volume for 24 hours after the operation. The demographic and perioperative variables including complications were compared among the three groups. Continuous variables were expressed as the mean \pm standard deviation and compared by analysis of variance. Categorical variables were compared by either the $\chi^{2}$ or Fisher's exact test. Age-sex adjusted odds ratios of the clinical variables associated with the development of complications were then estimated. In addition, the odds ratios of the drainage volume for the development of complication were estimated, respectively adjusting for several factors that were deemed of potential importance on the age-sex adjusted analysis. Owing to the small sample size and the presence of zero cells, we applied an exact logistic regression to estimate the odds ratios of the clinical variables for the development of complication ${ }^{9,10}$ inasmuch as regular logistic regression for the analysis of skewed or sparse data sets is unreliable. All statistical analyses were carried out with SAS version 8.02 (SAS Institute, Inc, Cary, NC) software package. ${ }^{11}$

\section{RESULTS}

\section{Demographic Data}

A VATS lobectomy was successfully performed in all patients, and there were no conversions to an open thoracotomy. The subjects accounted for $60 \%$ of the patients undergoing a VATS major pulmonary resection at our hospital. After the operation, 36 patients who had an air leak $(\mathrm{n}=34)$, malignant effusion showing gradual increase $(n=1)$, or chylothorax showing cloudy effusion $(n=1)$ were excluded from this study. The remaining 100 patients underwent an early removal of the $28 \mathrm{~F}$ chest tube on the day after the operation, independent of the drainage volume (median, $330 \mathrm{~mL}$; range, $60-1030 \mathrm{~mL}$ ).

The median subject age was 68 years (range, 30-86 years); 26 patients were aged 75 years or older. The subjects included 45 women and 55 men. A poor functional status, as defined by a performance status of 2 , was seen in 2 patients. A smoking history was present in 60 patients (mean packyears of tobacco smoking, 47). The mean forced expiratory volume in 1 second was $2.2 \mathrm{~L}$ (range, 1.2-3.9 L). The comorbidity of this series included 17 patients with chronic obstructive pulmonary disease, 10 patients with diabetes mellitus, 6 patients with interstitial pneumonia, and 6 patients with long-standing pleuritis. No patients underwent steroid therapy. The preoperative stages were as follows: IA in 55 patients, IB in 27, IIA in 2, IIB in 10, IIIA in 4, and IV in 2 . The demographic variables showed no differences among the three groups according to the drainage volume $(0-289 \mathrm{~mL}, \mathrm{n}=33 ; 290-399 \mathrm{~mL}, \mathrm{n}=33$; and $\geq 400$ $\mathrm{mL}, \mathrm{n}=34)($ Table 1$)$.

\section{Perioperative Data}

The thoracoscopic exploration showed a broad pleural adhesion in 15 patients. The treatment modality was a lobectomy in 96 patients and a bilobectomy in 4 patients. The distribution of the lobectomies was as follows: right upper lobe in 25 patients, middle lobe in 3, right lower lobe in 25 , right upper and middle lobe in 2 , right middle and lower lobe in 2, left upper lobe in 24, and left lower lobe in 19. The mean number of anatomic pulmonary segments resected was $4.3 \pm 1.0$ segments. The mean operative time and bleeding volume were $295 \pm 77$ minutes and $114 \pm 96 \mathrm{~mL}$, respectively. The pathologic analysis included primary lung cancer in 90 patients, secondary lung cancer in 4, and benign tumor in 6 . In the 90 patients with primary lung cancer, the postoperative stages were as follows: IA in 43 patients, IB in 17, IIA in 5, IIB in 4, IIIA in 9, IIIB in 9, and IV in 3 (Table 2).

No mortality was observed. There were 18 complications in 16 patients. Those complications were seen in patients with only primary lung cancer, although all the subjects underwent uniform surgical treatment consisting of 
TABLE 1. Demographic data according to the drainage volume for 24 hours

\begin{tabular}{|c|c|c|c|c|}
\hline \multirow[b]{3}{*}{ Variable } & \multicolumn{3}{|c|}{ Drainage volume $(\mathrm{mL})$} & \multirow[b]{3}{*}{$\begin{array}{c}P \\
\text { value }\end{array}$} \\
\hline & 0-289 & 290-399 & $\geq 400$ & \\
\hline & $\begin{array}{c}205.8 \pm 50.6 \\
(60-285) \\
(n=33)\end{array}$ & $\begin{array}{c}333.8 \pm 34.4 \\
(290-390) \\
(n=33)\end{array}$ & $\begin{array}{c}519.6 \pm 127.4 \\
(400-1030) \\
(n=34)\end{array}$ & \\
\hline Age (y) & $66.0 \pm 7.9$ & $67.7 \pm 12.2$ & $67.9 \pm 9.4$ & $.678^{*}$ \\
\hline Sex: male & $16(48 \%)$ & $16(48 \%)$ & $23(68 \%)$ & $.189 \dagger$ \\
\hline $\begin{array}{l}\text { Performance } \\
\text { status: } 0\end{array}$ & $31(94 \%)$ & $29(88 \%)$ & $31(91 \%)$ & $.291 \ddagger$ \\
\hline $\begin{array}{c}\text { Tobacco use } \\
\text { (pack-y) }\end{array}$ & $25.7 \pm 32.3$ & $31.3 \pm 30.0$ & $28.0 \pm 23.9$ & $.728 *$ \\
\hline COPD & $3(9 \%)$ & $7(21 \%)$ & $7(21 \%)$ & $.335 \dagger$ \\
\hline $\begin{array}{l}\text { Affected side: } \\
\text { right }\end{array}$ & $16(48 \%)$ & $20(61 \%)$ & $21(62 \%)$ & $.480 \dagger$ \\
\hline $\begin{array}{l}\text { Tumor in lower } \\
\text { lobe }\end{array}$ & $12(36 \%)$ & $15(45 \%)$ & $19(56 \%)$ & $.276 \dagger$ \\
\hline \multicolumn{5}{|c|}{ Preoperative stage } \\
\hline $\mathrm{I}(\mathrm{A}, \mathrm{B})$ & $23(19,4)$ & $27(14,13)$ & $32(22,10)$ & $.152 \ddagger$ \\
\hline II $(\mathrm{A}, \mathrm{B})$ & $7(1,6)$ & $4(1,3)$ & $1(0,1)$ & \\
\hline III $(\mathrm{A}, \mathrm{B})$ & $2(2,0)$ & $1(1,0)$ & $1(1,0)$ & \\
\hline IV & 1 & 1 & 0 & \\
\hline
\end{tabular}

a lobectomy with an extensive dissection of the mediastinal lymph nodes. The distribution of complications is shown in Table 2. The 2 patients who had pneumonia had undergone a right lower lobectomy. One had poor pulmonary reserve after a contralateral lobectomy and another contracted a chlamydial infection after discharge. All 4 patients who had late pleural effusion requiring thoracentesis had also undergone a right lower lobectomy (Table 3), although the remaining 96 patients had no trouble with pleural effusion. Only 1 patient underwent rescue drainage through the $7 \mathrm{~F}$ tube, although 99 patients underwent the removal of an unused $7 \mathrm{~F}$ small tube on the fourth postoperative day. The detrimental event of the patient was identified as a late pleural effusion requiring thoracentesis. Another patient who had a drainage volume of more than $1000 \mathrm{~mL}$ for 24 hours after surgery underwent removal of the chest tube because he finally met the
TABLE 2. Perioperative data according to the drainage volume for 24 hours

\begin{tabular}{|c|c|c|c|c|}
\hline \multirow[b]{2}{*}{ Variable } & \multicolumn{3}{|c|}{ Drainage volume (mL) } & \multirow[b]{2}{*}{$\begin{array}{c}P \\
\text { value } \\
\end{array}$} \\
\hline & $\begin{array}{c}0-289 \\
(n=33)\end{array}$ & $\begin{array}{l}290-399 \\
(n=33)\end{array}$ & $\begin{array}{c}\geq 400 \\
(n=34)\end{array}$ & \\
\hline Broad pleural adhesion & $3(9 \%)$ & $5(15 \%)$ & $7(21 \%)$ & $.447 \ddagger$ \\
\hline No. of segments resected & $4.2 \pm 1.0$ & $4.4 \pm 1.0$ & $4.3 \pm 1.0$ & $.686^{*}$ \\
\hline Operative time (min) & $310 \pm 79$ & $281 \pm 73$ & $293 \pm 81$ & $.315^{*}$ \\
\hline Bleeding volume (mL) & $89 \pm 70$ & $105 \pm 71$ & $149 \pm 126$ & $.027 *$ \\
\hline Primary lung cancer & $31(94 \%)$ & $28(85 \%)$ & $31(91 \%)$ & $.585 \ddagger$ \\
\hline \multicolumn{5}{|l|}{ Postoperative stage } \\
\hline $\mathrm{I}(\mathrm{A}, \mathrm{B})$ & $17(14,3)$ & $22(14,8)$ & $21(15,6)$ & $.254 \ddagger$ \\
\hline II $(\mathrm{A}, \mathrm{B})$ & $5(2,3)$ & $0(0,0)$ & $4(3,1)$ & \\
\hline III $(\mathrm{A}, \mathrm{B})$ & $8(5,3)$ & $5(1,4)$ & $5(3,2)$ & \\
\hline IV & 1 & 1 & 1 & \\
\hline $\begin{array}{l}\text { Epidural tube } \\
\text { duration (d) }\end{array}$ & $1.4 \pm 1.1$ & $1.4 \pm 1.1$ & $1.2 \pm 0.4$ & $.763^{*}$ \\
\hline $\begin{array}{l}\text { Analgesic requirement } \\
\quad \text { (times/wk) }\end{array}$ & $8.0 \pm 5.8$ & $5.8 \pm 4.4$ & $6.9 \pm 5.0$ & $.217^{*}$ \\
\hline Complication & $6(18 \%)$ & $5(15 \%)$ & $5(15 \%)$ & $.915 \dagger$ \\
\hline Atrial fibrillation & 2 & 2 & 0 & \\
\hline Ileus & 0 & 0 & 1 & \\
\hline $\begin{array}{l}\text { Pleural effusion } \\
\text { requiring thoracentesis }\end{array}$ & 1 & 1 & 2 & \\
\hline Pneumonia & 2 & 0 & 0 & \\
\hline Pneumothorax & 1 & 0 & 2 & \\
\hline $\begin{array}{l}\text { Sputum retention } \\
\text { requiring bronchoscopy }\end{array}$ & 29 & 2 & 0 & \\
\hline Postop hospital stay (d) & $12.3 \pm 7.3$ & $11.5 \pm 4.5$ & $13.1 \pm 8.9$ & $.647^{*}$ \\
\hline
\end{tabular}

early removal criteria after the dilution of his bloody effusion was confirmed. No associations between the surgical site and complications were observed, except for pneumonia and the late pleural effusion. No subjects had pleural infectious disease such as empyema at a mean follow-up of 34 months after the operation in this study. No perioperative variables, except for bleeding volume, showed any differences among the three groups according to the drainage volume (Table 2).

TABLE 3. Characteristics of the 4 patients requiring thoracentesis

\begin{tabular}{|c|c|c|c|c|c|c|c|}
\hline $\begin{array}{l}\text { Patient No. } \\
\text { (age }[y], \text { sex) }\end{array}$ & $\begin{array}{c}\text { Disease } \\
\text { and stage }\end{array}$ & Surgery & $\begin{array}{c}\text { Bleeding during } \\
\text { surgery }(\mathbf{m L})\end{array}$ & $\begin{array}{l}\text { Drainage volume } \\
\text { for } 24 \mathrm{~h} \text { after } \\
\text { surgery }(\mathrm{mL}) \\
\end{array}$ & $\begin{array}{c}\text { No. of days } \\
\text { until thoracentesis } \\
\text { after surgery } \\
\end{array}$ & $\begin{array}{l}\text { Indication } \\
\text { including } \\
\text { symptoms } \\
\end{array}$ & $\begin{array}{c}\text { Volume of } \\
\text { thoracentesis } \\
\text { fluid }(\mathbf{m L}) \\
\end{array}$ \\
\hline $1(52, M)$ & PLC, IA & RLL & 60 & 580 & $4 *$ & Compression atelectasis & 270 \\
\hline $2(59, M)$ & PLC, IB & RLL & 125 & 1030 & 22 & Cough & 420 \\
\hline $3(74, F)$ & PLC, IV & RLL & 70 & 205 & 8 & Compression atelectasis & 300 \\
\hline $4(80, M)$ & PLC, IA & RLL & 100 & 295 & 11,14 & Chest compression & 970,700 \\
\hline
\end{tabular}

$P t$, Patient; $M$, male; $F$, female; $P L C$, primary lung cancer; $R L L$, right lower lobectomy. $*$ The patient underwent rescue drainage through the $7 \mathrm{~F}$ tube on postoperative day 4. 


\section{Association of Drainage Volume and Complication}

The age-sex adjusted odds ratios of the clinical variables associated with the development of complications are presented in Table 4. The variables that were deemed of potential importance on the age-sex adjusted analysis were tumor location, preoperative stage, the number of anatomic segments resected, and the severity of the disease. The patients with a tumor in a lower lobe had a higher odds ratio for complication than did those with a tumor in the upper or middle lobe. A preoperative stage of II or higher also showed a higher odds ratio than in stage I. The number of segments resected was also associated with the risk of complication. The subjects with advanced disease had a higher odds ratio than those with localized disease. When the analyses were limited to the subjects with primary cancer, advanced disease of postoperative stage II to IV also showed a higher odds ratio (5.66; 95\% confidence interval, $1.55-23.95 ; P=.0061)$ than did localized disease of postoperative stage I.

On the other hand, the drainage volume was not associated with increased morbidity. Furthermore, the multivariable odds ratios of the drainage volume adjusted for tumor location, preoperative stage, number of segments resected, or severity showed no association with the development of complications (Table 5).

\section{DISCUSSION}

After an uncomplicated VATS wedge resection of the lung, Russo and associates ${ }^{8}$ have reported that the early removal of chest tubes, within 90 minutes of surgery, allowed for less postoperative pain, fewer chest radiographs, and earlier discharge from the hospital than the traditional tube management, regardless of comparable morbidity. Lately, several studies on postoperative management without use of chest tubes after a VATS minor operation have demonstrated that the lack of tube drainage was not associated with any increased morbidity, and this protocol resulted in shorter hospital stays than did traditional tube management. ${ }^{12,13}$ Each study has emphasized that this early postoperative drainage management is a safe and effective practice in well-selected patients, absent an air leak or increased drainage including bleeding. The fluid collection in the dead space after a wedge resection may be negligibly small. The benefits of VATS, such as smaller incisions and reduced trauma, may also be responsible for the fluid collection. The early removal of chest tubes is likely be more economical and less painful than the traditional tube management, if it is successful after a VATS major pulmonary resection.

With regard to a major pulmonary resection, there are precious few reports addressing the issue of the early removal of chest tubes after a lobectomy. Generally, the decision to remove the tube is likely to be based on the lack of air leak, the
TABLE 4. Age-sex adjusted odds ratios of the clinical variables associated with the development of complications

\begin{tabular}{|c|c|c|c|c|c|}
\hline Variable & No. & $\begin{array}{c}\text { No. of } \\
\text { patients } \\
\text { with PC }(\%)\end{array}$ & $\begin{array}{l}\text { Odds } \\
\text { ratio }\end{array}$ & $\begin{array}{c}95 \% \\
\text { CI }\end{array}$ & $\begin{array}{c}P \\
\text { value }\end{array}$ \\
\hline \multicolumn{6}{|c|}{ Drainage volume (mL) } \\
\hline $0-289$ & 33 & $6(18.2 \%)$ & Reference & & \\
\hline 290-399 & 33 & $5(15.2 \%)$ & 0.71 & $0.14-3.36$ & .875 \\
\hline$\geq 400$ & 34 & $5(14.7 \%)$ & 0.62 & $0.13-2.85$ & .701 \\
\hline Age & & & 1.04 & $0.98-1.11$ & .170 \\
\hline \multicolumn{6}{|l|}{ Sex } \\
\hline Female & 45 & $4(8.9 \%)$ & Reference & & \\
\hline Male & 55 & $12(21.8 \%)$ & 2.83 & $0.78-13.04$ & .135 \\
\hline \multicolumn{6}{|l|}{ Performance status } \\
\hline 0 & 91 & $13(14.3 \%)$ & Reference & & \\
\hline 1 or 2 & 9 & $3(33.3 \%)$ & 2.22 & $0.27-15.00$ & .582 \\
\hline \multicolumn{6}{|l|}{ COPD } \\
\hline No & 83 & $11(13.3 \%)$ & Reference & & \\
\hline Yes & 17 & $5(29.4 \%)$ & 2.30 & $0.52-9.07$ & .312 \\
\hline \multicolumn{6}{|l|}{ Tumor location } \\
\hline Upper or middle & 54 & $3(5.6 \%)$ & Reference & & \\
\hline Lower & 46 & $13(28.3 \%)$ & 6.01 & $1.44-36.38$ & .010 \\
\hline \multicolumn{6}{|l|}{ Preoperative stage } \\
\hline I & 82 & $9(11.0 \%)$ & Reference & & \\
\hline II-IV & 18 & $7(38.9 \%)$ & 4.42 & $1.11-17.32$ & .034 \\
\hline \multicolumn{6}{|l|}{ Pleural adhesion } \\
\hline No or narrow & 85 & $13(15.3 \%)$ & Reference & & \\
\hline Broad & 15 & $3(20.0 \%)$ & 1.08 & $0.16-5.37$ & 1.000 \\
\hline \multicolumn{6}{|c|}{ No. of segments resected } \\
\hline $0-3$ & 26 & $0(0 \%)$ & Reference & & \\
\hline $3.1-4.9$ & 21 & $4(19.0 \%)$ & 7.77 & 0.88 -infinity & .067 \\
\hline$\geq 5$ & 53 & $12(22.6 \%)$ & 9.31 & 1.40-infinity & .017 \\
\hline \multicolumn{6}{|l|}{ Operative time (min) } \\
\hline $0-255$ & 33 & $4(12.1 \%)$ & Reference & & \\
\hline $256-315$ & 33 & $4(12.1 \%)$ & 0.86 & $0.14-5.18$ & 1.000 \\
\hline$\geq 316$ & 34 & $8(23.5 \%)$ & 1.77 & $0.40-9.28$ & .603 \\
\hline \multicolumn{6}{|l|}{ Bleeding volume (mL) } \\
\hline $0-60$ & 35 & $1(2.9 \%)$ & Reference & & \\
\hline $61-125$ & 31 & $7(22.6 \%)$ & 8.33 & $0.96-399.53$ & .057 \\
\hline$\geq 126$ & 34 & $8(23.5 \%)$ & 6.46 & $0.71-321.47$ & .131 \\
\hline \multicolumn{6}{|l|}{ Disease } \\
\hline Primary cancer & 90 & $16(17.8 \%)$ & Reference & & \\
\hline Secondary cancer & 4 & $0(0 \%)$ & 1.02 & $0.00-8.89$ & 1.000 \\
\hline Benign tumor & 6 & $0(0 \%)$ & 0.78 & $0.00-6.37$ & .840 \\
\hline \multicolumn{6}{|l|}{ Severity } \\
\hline Localized disease & 66 & $5(7.6 \%)$ & Reference & & \\
\hline Advanced disease & 34 & $11(32.4 \%)$ & 5.22 & $1.46-21.67$ & .008 \\
\hline
\end{tabular}

$P C$, Postoperative complication; $C I$, confidence interval; $C O P D$, chronic obstructive pulmonary disease; localized disease includes postoperative stage I primary lung cancer $(n=60)$ and benign tumor $(n=6)$; advanced disease includes postoperative stage II-IV primary lung cancer $(\mathrm{n}=30)$ and secondary cancer $(\mathrm{n}=4)$.

absence of a hemothorax, and drainage of less than $150 \mathrm{~mL}$ for the last 24 hours after a lobectomy through an open thoracotomy. ${ }^{1}$ In the patients who underwent a VATS major pulmonary resection, McKenna and coworkers ${ }^{14}$ have reported that early removal of the chest tube is feasible with minimal complications when the drainage is less than 300 
TABLE 5. Multivariable odds ratios of the drainage volume for development of complications

\begin{tabular}{|c|c|c|c|c|}
\hline Model & Variable & Odds ratio & $95 \% \mathrm{CI}$ & $P$ value \\
\hline \multirow[t]{7}{*}{1} & Drainage volume (mL) & & & \\
\hline & $0-289$ & Reference & & \\
\hline & $290-399$ & 0.53 & $0.09-2.77$ & .611 \\
\hline & $\geq 400$ & 0.37 & $0.06-1.98$ & .318 \\
\hline & Tumor location & & & \\
\hline & Upper or middle & Reference & & \\
\hline & Lower & 7.18 & $1.61-47.01$ & .006 \\
\hline \multirow[t]{7}{*}{2} & Drainage volume (mL) & & & \\
\hline & $0-289$ & Reference & & \\
\hline & 290-399 & 1.10 & $0.20-6.16$ & 1.000 \\
\hline & $\geq 400$ & 1.23 & $0.21-7.62$ & 1.000 \\
\hline & Preoperative stage & & & \\
\hline & I & Reference & & \\
\hline & II-IV & 4.57 & $1.01-21.15$ & .048 \\
\hline \multirow[t]{8}{*}{3} & Drainage volume $(\mathrm{mL})$ & & & \\
\hline & $0-289$ & Reference & & \\
\hline & $290-399$ & 0.68 & $0.13-3.32$ & .834 \\
\hline & $\geq 400$ & 0.56 & $0.11-2.76$ & .627 \\
\hline & No. of segments resectec & & & \\
\hline & $0-3$ & Reference & & \\
\hline & $3.1-4.9$ & 8.10 & $0.91-$ infinity & .061 \\
\hline & $\geq 5$ & 9.22 & 1.40-infinity & .017 \\
\hline \multirow[t]{7}{*}{4} & Drainage volume $(\mathrm{mL})$ & & & \\
\hline & $0-289$ & Reference & & \\
\hline & $290-399$ & 1.03 & $0.19-5.41$ & 1.000 \\
\hline & $\geq 400$ & 0.86 & $0.17-4.38$ & 1.000 \\
\hline & Severity & & & \\
\hline & Localized disease & Reference & & \\
\hline & Advanced disease & 4.97 & $1.34-20.77$ & .012 \\
\hline
\end{tabular}

Model 1 presents the odds ratio adjusted by age, sex, drainage volume, and tumor location. Model 2 presents the odds ratio adjusted by age, sex, drainage volume, and preoperative stage. Model 3 presents the odds ratio adjusted by age, sex, drainage volume, and number of segments resected. Model 4 presents the odds ratio adjusted by age, sex, drainage volume, and postoperative stage of primary lung cancer including benign tumor and secondary cancer. $C I$, Confidence interval; localized disease includes postoperative stage I primary lung cancer $(n=60)$ and benign tumor $(n=6)$; advanced disease includes postoperative stage II-IV primary lung cancer $(\mathrm{n}=30)$ and secondary cancer $(n=4)$.

$\mathrm{mL}$ for the preceding 24 hours. In the previously described two studies concerning an open thoracotomy, the safety margin of the drainage volume for the last 24 hours was empirically established as approximately $400 \mathrm{~mL} .^{2-4}$ This study, in which patients who had drainage volume exceeding the 400 $\mathrm{mL}$ accounted for one third of the subjects, showed that even excessive drainage volume was not associated with increased complication. Therefore, the drainage volume for removal may not be confined to $400 \mathrm{~mL}$ or less, although the early removal strategy of chest tubes must be strictly applied to the patient.

The pleural fluid originates from the parietal pleura and is resorbed by the visceral pleura. The pleural effusion develops when the amount of fluid that enters the pleural space exceeds the amount that can be removed. ${ }^{15}$ Therefore, the removal of a pulmonary lobe with a large pleural area, such as a right lower or left upper lobe, creates a temporary fluid resorption disturbance. The increased frequency of an excessive pleural effusion after a right lower lobectomy seems to be closely associated with middle lobe atelectasis. Because a large dead space exists in the dorsal and inferior divisions of the pleural cavity, the fluid is apt to accumulate under the influence of gravity. A middle lobe atelectasis often occurs because the middle lobe bronchus is spindly and also apt to become kinked in contrast to the lingular bronchus, and it accelerates an increased amount of pleural effusion. Intrathoracic bleeding, as a barrier to the visceral pleura either during or after surgery, may also decrease the amount of fluid that can be removed, as shown by Table 2, or by the presentation of patient 2 in Table 3. Although excessive suction with a negative pressure increases the amount of fluid that enters the pleural space, the established negative pressure of this series may not have been excessive because $96 \%$ of all subjects did not have any symptomatic pleural effusion.

With the re-expansion of the remaining lung after surgery, the pleural space is usually obliterated within several days to a week. In most instances, the fluid that remains is resorbed or becomes organized. Although an asymptomatic fluid accumulation occasionally remains for a long period, the disruption of the balance of the fluid movement leads to an excessive and symptomatic fluid collection in the pleural space. Conlan ${ }^{16}$ reported that $3 \%$ of persistent fluid spaces become complicated. No subjects in this study had pleural infectious disease such as empyema despite a mean follow-up of 34 months after surgery, although further careful surveillance is needed for some time in the future.

The main limitation of this study is the small cohort, and this study may be hard to accept for surgeons who engage in traditional tube management. We included all complications in the analyses owing to the small number of complications and ambiguity to define the complications related to pleural effusion. Further investigation of the complications limited to those related to the accumulation of pleural effusion is thus warranted. It is unknown whether the benefits of VATS allow the early removal of chest tubes, because this study does not include a comparative study with an open thoracotomy. However, this early removal management of the chest tube is a novel treatment protocol, which is considered to potentially improve the quality of life of postoperative patients.

The early removal of the chest tube on the day after a VATS lobectomy, independent of the drainage volume, appears to be a safe treatment protocol in well-selected patients without air leakage, increased drainage, cloudy effusion, atelectasis, or episodes of intrathoracic bleeding after surgery. Nevertheless, further careful surveillance is needed, especially for patients undergoing a right lower lobectomy. We believe that further investigation is warranted to confirm our findings and to help identify the optimal tube management protocol. 
We thank Professor Masamitsu Kido, Department of Respiratory Medicine, University of Occupational and Environmental Health, Japan, for his advice.

\section{References}

1. Caro AG, Roca MJ, Torres J, Cascales P, Terol E, Castaner J, et al. Successful use of a single chest drain postlobectomy instead of two classical drains: a randomized study. Eur J Cardiothorac Surg. 2006;29:562-6.

2. Cerfolio RJ, Pickens A, Bass C, Katholi C. Fast-tracking pulmonary resections. J Thorac Cardiovasc Surg. 2001;122:318-24.

3. Cerfolio RJ, Bryant AS. Results of a prospective algorithm to remove chest tubes after pulmonary resection with high output. J Thorac Cardiovasc Surg. 2008;135: 269-73.

4. Nomori H, Horio H, Suemasu K. Early removal of chest drainage tubes and oxygen support after a lobectomy for lung cancer facilitates earlier recovery of the 6-minute walking distance. Surg Today. 2001;31:395-9.

5. Nakanishi R, Hirai A, Muranaka K, Shinohara K. Successful video-assisted thoracic surgery lobectomy in a single-lung patient. Surg Laparosc Endosc Percutan Tech. 2007; 17:562-4.

6. Nakanishi R, Hirai A, Yamashita T, Oka S. Video-assisted thoracoscopic completion pneumonectomy for a second primary cancer: a case report. J Thorac Cardiovasc Surg. 2008;135:945-6.

7. Nakanishi R, Yamashita T, Oka S. Initial experience of video-assisted thoracic surgery lobectomy with partial removal of the pulmonary artery. Interact Cardiovasc Thorac Surg. 2008;7:996-1000.
8. Russo L, Wiechmann RJ, Magovern JA, Szydlowski GW, Mack MJ, Naunheim KS, et al. Early chest tube removal after video-assisted thoracoscopic wedge resection of the lung. Ann Thorac Surg. 1998;66:1751-4.

9. Mehta CR, Patel NR. Exact logistic regression: theory and examples. Stat Med.. 1995; 14:2143-60.

10. Derr RE. Performing exact logistic regression with the SAS system. Proceedings of the 25th Annual SAS Users Group International Conference, 2000; Paper 254, Cary (NC): SAS Institute Inc.

11. SAS Institute Inc. SAS/STAT user's guide, Release 6.03. Cary (NC): SAS Institute Inc; 1988.

12. Watanabe A, Watanabe T, Ohsawa H, Mawatari T, Ichimiya Y, Takahashi N, et al. Avoiding chest tube placement after video-assisted thoracoscopic wedge resection of the lung. Eur J Cardiothorac Surg. 2004;25:872-6.

13. Luckraz H, Rammohan KS, Phillips M, Abel R, Karthikeyan S, Kulatilake NEP, et al. Is an intercostal chest drain necessary after video-assisted thoracoscopic lung biopsy? Ann Thorac Surg. 2007;84:237-9.

14. McKenna RJ Jr, Mahtabifard A, Pickens A, Kusuanco D, Fuller CB. Fast-tracking after video-assisted thoracoscopic surgery lobectomy, segmentectomy, and pneumonectomy. Ann Thorac Surg. 2007;84:1663-8.

15. Light RW. Physiology of pleural fluid production and benign pleural effusion. In: Shields TW, LoCicero J III, Ponn RB, eds. General thoracic surgery. Volume 1. 5th ed. Philadelphia: Lippincott Williams \& Wilkins; 2000. p. 687-98.

16. Conlan AA. Prophylaxis and management of postlobectomy infected spaces. In Deslauriers J, Lacquet LK, eds. Thoracic surgery: surgical management of pleural diseases. St Louis: CV Mosby; 1990. p. 279 